\title{
Towards Objectification of Multi-Criteria Assessments: a Comparative Study on MCDA Methods
}

\author{
Aleksandra Bączkiewicz*, Jarosław Wątróbski \\ Institute of Management, University of Szczecin, \\ ul. Cukrowa 8, 71-004 Szczecin, Poland \\ *Doctoral School of University of Szczecin, \\ ul. Mickiewicza 16, 70-383 Szczecin, Poland \\ Email: aleksandra.baczkiewicz@phd.usz.edu.pl \\ jaroslaw.watrobski@usz.edu.pl
}

\author{
Bartłomiej Kizielewicz, Wojciech Sałabun \\ Research Team on Intelligent Decision Support Systems, \\ Department of Artificial Intelligence Methods and Applied Mathematics, \\ Faculty of Computer Science and Information Technology \\ West Pomeranian University of Technology in Szczecin \\ ul. Żołnierska 49, 71-210 Szczecin, Poland \\ Email: \{bartlomiej-kizielewicz,wojciech.salabun\}@ zut.edu.pl
}

\begin{abstract}
Objective evaluation in problems considering many, often conflicting criteria is challenging for the decision-maker. This paper presents an approach based on MCDA methods to objectify evaluations in the camera selection problem. The proposed approach includes three MCDA methods, TOPSIS, VIKOR, COMET, and two criterion weighting techniques. Two ranking similarity coefficients were used to compare the resulting rankings of the alternatives: $W S$ and $r_{w}$. The performed research confirmed the importance of the appropriate selection of multicriteria decision-making methods for the solved problem and the relevance of comparative analysis in method selection and construction of objective rankings of alternatives.
\end{abstract}

\section{INTRODUCTION}

$\mathbf{D}^{1}$ EALING with complex, real-world decision-making problems involves recognizing conflicting goals, making decisions with multiple criteria, and aiming for compromise solutions [1], [2]. In response to these requirements, many solutions dedicated to selected areas and general-purpose methods have been developed. Most research has focused on developing and improving new MCDA methods. They differ in many aspects, such as different techniques for determining the weights of criteria in the calculations, the complexity of the algorithms, the way preferences and evaluation criteria are represented, the type of data aggregation and the possibility of considering uncertain data [3].

Despite the existence of many MCDA methods, it is important to be aware that no method is perfect and can be considered suitable for applying to every decision situation or solving every decision problem [4], [5]. In such a condition, it becomes a significant research problem to select a decision support method suitable for the problem under consideration since only a properly selected method can provide a proper solution that reflects the decision maker's preferences [6]. The assessment of alternatives performed using MCDA methods requires considering the decision maker's preferences, which means that the final recommendation may change depending on those preferences [7].
Although there is observed a dynamic development of new MCDA methods and improved existing algorithms, relatively little attention is paid to their proper selection for a given decision problem. Applying the inappropriate method to a particular decision situation can reduce the quality of the recommendation, as different MCDA methods produce inconsistent results. Furthermore, the complexity, unrepeatability, or the fact that decision situations may occur simultaneously over a short time makes their analysis challenging. Consequently, it becomes necessary to apply formal procedures and guidelines for selecting MCDA methods in case of a partial lack of knowledge of the decision situation [8], [9].

Common real-life decision problems in which MCDA methods are applied to solve are issues like the mobile devices selection problem. Among them, there can be considered the mobile phone selection problem, the mobile handset selection problem, laptop selection problem, camera selection problem, where criteria can be features and functionalities such as the size of the in-build camera, battery talk time, brand, colour, camera size and resolution [10].

There are many methods of multi-criteria decision making belonging to different streams. Among them, the two main streams, i.e. the American school and the European school, stand out the most. In addition, there is also an approach that combines elements of both groups and the approach based on a set of rules. Examples of multi-criteria decision-making methods and their assignment to different streams (American, European, mixed or rule-based) are presented using a Table I.

This paper aims to present the study case of an objective camera selection multi-criteria problem. The authors' main objective was to perform a comparative analysis of the results obtained using three selected MCDA methods. Due to the goal of obtaining objective results in an automated process, the authors decided to choose two objective criteria weighting methods. It was assumed that due to the differences in the algorithms included in the MCDA methods, which cause 
TABLE I

MULTI-CRITERIA DECISION-MAKING METHODS WITH STREAM AFFILIATIONS AND REFERENCES.

\begin{tabular}{|c|c|c|c|}
\hline Stream & Acronym & Method Name & References \\
\hline \multirow{3}{*}{ European } & ELECTRE & ELimination Et Choix Traduisant la REalité (ELimination Et Choice Translating REality) & [11] \\
\hline & PROMETHEE & Preference Ranking Organization METHod for Enrichment of Evaluations & [12] \\
\hline & TACTIC & Treatment of the Alternatives according To the Importance of Criteria & [13] \\
\hline \multirow{4}{*}{ American } & AHP & Analytic hierarchy process & [14] \\
\hline & TOPSIS & Technique for the Order of Prioritisation by Similarity to Ideal Solution & [15] \\
\hline & VIKOR & VIseKriterijumska Optimizacija I Kompromisno Resenje & [16] \\
\hline & SMART & Simple Mutli-Attribute Rating Technique & [17] \\
\hline \multirow{3}{*}{ Mixed } & IDRA & Intercriteria Decision Rule Approach & [18] \\
\hline & EVAMIX & Evaluation of Mixed Data & [19] \\
\hline & PACMAN & Passive and Active Compensability Multicriteria ANalysis & [20] \\
\hline Rule based & $\begin{array}{c}\text { DRSA } \\
\text { COMET }\end{array}$ & $\begin{array}{c}\text { Dominance-based rough set approach } \\
\text { Characteristic Objects METhod }\end{array}$ & $\begin{array}{c}{[21]} \\
{[22],[23]}\end{array}$ \\
\hline
\end{tabular}

various methods to provide different solutions to the same problems, benchmarking with several methods is an important stage in evaluating a multi-criteria problem. Because MCDA methods are intended to be used in many different fields, the need for a customized approach that considers the particular nature of the problem being analyzed occurs [24]. Using the correlation coefficients of the rankings in the next step allows an objective assessment of the convergence of the rankings and identification of methods that give consistent and outlier results in a specific problem.

For the solution of a described problem, a model-based approach including three MCDA methods, TOPSIS, VIKOR and COMET, has been applied, taking into account two techniques for determining the criteria weights: Mean Weighting, which gives equal weights and Entropy Weighting.

The rest of the paper is organized as follows. Section II provides the preliminaries and main fundamentals of the TOPSIS, VIKOR and COMET methods. In Section III, the study case, including evaluating alternatives and their types, is presented. Section IV shows the results of the performed assessment of alternatives. There is also presented the influence of the methods used in the authors' approach to the outcomes. Section V contains the summary of the conducted survey and conclusions.

\section{PRELIMINARIES}

\section{A. The TOPSIS Method}

The TOPSIS method compares the relative distances between the evaluated alternatives and the positive ideal solution (PIS) and the anti-ideal solution (negative ideal solution NIS). The goal is to rank the alternatives such that the best alternative is as close as possible to the PIS and as far as possible from the NIS [25]. The TOPSIS method includes the five stages given below [26].

Step 1. Decision matrix is normalized.

In this approach, the greatest and the least values in the considered set are used. The formulas are described as follows (1) and (2):

$$
r_{i j}=\frac{x_{i j}-\min _{j}\left(x_{i j}\right)}{\max _{j}\left(x_{i j}\right)-X_{m i n}}
$$

$$
r_{i j}=\frac{\max _{j}\left(x_{i j}\right)-x_{i j}}{\max _{j}\left(x_{i j}\right)-\min _{j}\left(x_{i j}\right)}
$$

Step 2. Weighted values of the normalized decision matrix $v_{i j}$ are determined according to the Equation (3).

$$
v_{i j}=w_{i} r_{i j}
$$

Step 3. Calculate the positive ideal solution (PIS) values and negative anti-ideal solution (NIS) vectors. The PIS represented by the vector (4) expresses the maximum values for each criterion, and the NIS is represented by the vector (5) minimum values. It is unnecessary to divide the criteria into cost and profit criteria in this step because the cost criteria were transformed to profit criteria in the normalization step.

$$
\begin{aligned}
& v_{j}^{+}=\left\{v_{1}^{+}, v_{2}^{+}, \ldots, v_{n}^{+}\right\}=\left\{\max _{j}\left(v_{i j}\right)\right\} \\
& v_{j}^{-}=\left\{v_{1}^{-}, v_{2}^{-}, \ldots, v_{n}^{-}\right\}=\left\{\min _{j}\left(v_{i j}\right)\right\}
\end{aligned}
$$

Step 4. Calculate distance from PIS according to the Equation (6) and NIS, using the Equation (7) for each of the alternatives considered [6].

$$
\begin{aligned}
& D_{i}^{+}=\sqrt{\sum_{j=1}^{n}\left(v_{i j}-v_{j}^{+}\right)^{2}} \\
& D_{i}^{-}=\sqrt{\sum_{j=1}^{n}\left(v_{i j}-v_{j}^{-}\right)^{2}}
\end{aligned}
$$

Step 5. Calculate the outcome for each of the respected alternatives according to Equation (8). This score takes values between 0 and 1 . Thus, the closer the value of a given alternative is to 1 , the better is the alternative.

$$
C_{i}=\frac{D_{i}^{-}}{D_{i}^{-}+D_{i}^{+}}
$$




\section{B. The VIKOR Method}

The VIKOR method (VlseKriterijumska Optimizacija I Kompromisno Resenje), similarly to TOPSIS, takes distance measurement into account, but in this approach, the goal is to identify the alternative closest to the ideal solution. Therefore, the solution sought is a compromise solution [6]. The five steps of the VIKOR method are described below [27], [28], [29].

Step 1. Determinate the best $f_{j}^{*}$ and the worst $f_{j}^{-}$value for the function of a particular criterion. For profit criteria, the Equation is used (9).

$$
f_{j}^{*}=\max _{i} f_{i j}, \quad f_{j}^{-}=\min _{i} f_{i j}
$$

whereas in the case of the cost criteria, the following Equation is used (10).

$$
f_{j}^{*}=\min _{i} f_{i j}, \quad f_{j}^{-}=\max _{i} f_{i j}
$$

Step 2. Calculate $S_{i}$ and $R_{i}$ with using Equations (11) and (12).

$$
\begin{gathered}
S_{i}=\sum_{j=1}^{n} w_{j}\left(f_{j}^{*}-f_{i j}\right) /\left(f_{j}^{*}-f_{j}^{-}\right) \\
R_{i}=\max _{j}\left[w_{j}\left(f_{j}^{*}-f_{i j}\right) /\left(f_{j}^{*}-f_{j}^{-}\right)\right]
\end{gathered}
$$

Step 3. Calculate $Q_{i}$ with using Equation (13).

$$
Q_{i}=v\left(S_{i}-S^{*}\right) /\left(S^{-}-S^{*}\right)+(1-v)\left(R_{i}-R^{*}\right) /\left(R^{-}-R^{*}\right)
$$

where

$S^{*}=\min _{i} S_{i}, \quad S^{-}=\max _{i} S_{i}$

$R^{*}=\min _{i} R_{i}, \quad R^{-}=\max _{i} R_{i}$

$v$ means the weight adopted for the strategy of "most criteria".

Step 4. Ranked alternatives $S, R$ and $Q$ are ordered in ascending order. Three ranked lists are the outcome.

Step 5. A compromise solution is proposed considering the conditions of good advantage and acceptable stability within the three vectors obtained in the previous step [29]. The best alternative is the one with the lowest value and the leading position in the ranking $Q$ [30].

\section{The COMET Method}

The main advantage of the Characteristic Objects METhod (COMET) is its resistance to the rank reversal paradox [31]. COMET method considers fuzzy sets theory. The important steps of this method are the determination and comparison of characteristic objects and the creation of a rule base. Then, each alternative is evaluated in a defuzzification process [25]. The five stages that the COMET method involves are provided below [32], [33], [34].

Step 1. Definition of the space of the problem. The expert determines the dimensionality of the problem with the selection $r$ criteria, $C_{1}, C_{2}, \ldots, C_{r}$. Then a set of fuzzy numbers is selected for each criterion $C_{i}$, e.g. $\left\{\tilde{C}_{i 1}, \tilde{C}_{i 2}, \ldots, \tilde{C}_{i c_{i}}\right\}$ according to the Equation (14).

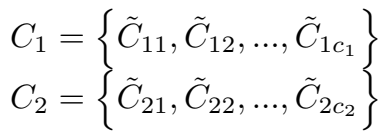

$$
\begin{aligned}
& C_{r}=\left\{\tilde{C}_{r 1}, \ddot{C}_{r 2}, \ldots, \tilde{C}_{r c_{r}}\right\}
\end{aligned}
$$

where $C_{1}, C_{2}, \ldots, C_{r}$ are the ordinals of the fuzzy numbers for all criteria.

Step 2. The generation of characteristic objects $(C O \mathrm{~s})$ with the usage of the Cartesian product of the fuzzy numbers' cores of all the criteria according to the Equation (15).

$$
C O=\left\langle C\left(C_{1}\right) \times C\left(C_{2}\right) \times \ldots C\left(C_{r}\right)\right\rangle
$$

As a result, an ordered set of all COs is obtained (16).

$$
\begin{gathered}
C O_{1}=\left\langle C\left(\tilde{C}_{11}\right), C\left(\tilde{C}_{21}\right), \ldots, C\left(\tilde{C}_{r 1}\right)\right\rangle \\
C O_{2}=\left\langle C\left(\tilde{C}_{11}\right), C\left(\tilde{C}_{21}\right), \ldots, C\left(\tilde{C}_{r 2}\right)\right\rangle \\
\ldots \\
C O_{t}=\left\langle C\left(\tilde{C}_{1 c_{1}}\right), C\left(\tilde{C}_{2 c_{2}}\right), \ldots, C\left(\tilde{C}_{r c_{r}}\right)\right\rangle
\end{gathered}
$$

where $t$ is the count of $C O \mathrm{~s}$ and is equal to Equation (17).

$$
t=\prod_{i=1}^{r} c_{i}
$$

Step 3. Assessment of characteristic objects by identifying the Matrix of Expert Judgment $M E J$ by comparing pairwise objects $C O$ s by the expert. The $M E J$ matrix is presented as Equation (18).

$$
M E J=\left(\begin{array}{cccc}
\alpha_{11} & \alpha_{12} & \ldots & \alpha_{1 t} \\
\alpha_{21} & \alpha_{22} & \ldots & \alpha_{2 t} \\
\ldots & \ldots & \ldots & \ldots \\
\alpha_{t 1} & \alpha_{t 2} & \ldots & \alpha_{t t}
\end{array}\right)
$$

where $\alpha_{i j}$ is the outcome of comparing $C O_{i}$ and $C O_{j}$ by the expert. The more preferred characteristic object receives a value of 1 , and the less preferred object receives a value of 0 . If the preferences are equal, both objects get a value of half. This step depends totally on the expert's knowledge and can be represented as (19).

$$
\alpha_{i j}= \begin{cases}0.0, & f_{\exp }\left(C O_{i}\right)<f_{\text {exp }}\left(C O_{j}\right) \\ 0.5, & f_{\exp }\left(C O_{i}\right)=f_{\exp }\left(C O_{j}\right) \\ 1.0, & f_{\exp }\left(C O_{i}\right)>f_{\exp }\left(C O_{j}\right)\end{cases}
$$

where the expert function $f_{\text {exp }}$ denotes the empirical preferences of the expert.

After the $M E J$ matrix is provided, a vertical vector of the Summed Judgments $S J$ is obtained as shown by Equation 20.

$$
S J_{i}=\sum_{j=1}^{t} \alpha_{i j}
$$

Finally, preference values are determined for each characteristic object. As a result, a vertical vector $P$ is obtained, where the $i$-th row contains the approximate value of preference for $\mathrm{CO}_{i}$. 
Step 4. Each $C O$ and its preference value is converted to a fuzzy rule by using the following Equation (21)

$$
\begin{array}{lllllll}
I F & C\left(\tilde{C}_{1 i}\right) & A N D & C\left(\tilde{C}_{2 i}\right) & A N D & \ldots & T H E N
\end{array}
$$

In this procedure, a complete fuzzy rule base is prepared.

Step 5. Inference and getting the final ranking. Each alternative is represented as a set of values, e.g.

$A_{i}=\left\{\alpha_{i 1}, \alpha_{i 2}, \alpha_{r i}\right\}$. This set refers to the criteria $C_{1}, C_{2}, \ldots, C_{r}$. Mamdani's fuzzy inference technique is used to determine the preference of the $i$-th decision variant. The constant rule base guarantees that the results obtained are unequivocal, which makes COMET completely resistant to the rank reversal paradox [35].

\section{Entropy Weighting Method}

In the entropy weighting method, the criteria weight is calculated using a measure of uncertainty in the information [36].

Step 1. Normalization of input data using sum normalization method (22).

$$
p_{i j}=\frac{x_{i j}}{\sum_{i=1}^{m} x_{i j}} i=1, \ldots, m ; j=1, \ldots, n
$$

Step 2. Calculation of the entropy value of $j$ th criterion using Equation (23).

$$
E_{j}=-\frac{\sum_{i=1}^{m} p_{i j} \ln \left(p_{i j}\right)}{\ln (m)} j=1, \ldots, n
$$

Step 3. Calculation of the objective weight of $j$ th criterion according to the Equation (24).

$$
w_{j}=\frac{1-E_{j}}{\sum_{i=1}^{n}\left(1-E_{j}\right)} j=1, \ldots, n
$$

\section{E. Mean Weighting Method}

Criteria weights are calculated according to the Equation (25), where $n$ is the number of criteria [37].

$$
w_{j}=1 / n
$$

\section{F. Weighted Spearman's Rank Correlation Coefficient}

The symmetrical $r_{w}$ correlation coefficient is calculated by the Equation (26). The sample size is $N$ and $x_{i}$ and $y_{i}$ are the positions in rankings which are compared [38].

$$
r_{w}=1-\frac{6 \sum_{i=1}^{N}\left(x_{i}-y_{i}\right)^{2}\left(\left(N-x_{i}+1\right)+\left(N-y_{i}+1\right)\right)}{N^{4}+N^{3}-N^{2}-N}
$$

\section{G. The WS similarity coefficient}

The asymmetrical $W S$ similarity coefficient is calculated according to Equation (27), where $N$ is size of sample and $x_{i}$ and $y_{i}$ are the positions in the compared rankings $x$ and $y$.

$P_{i}$ For this coefficient, changes in the positions at the top of the ranking influence most significantly its value [39].

$$
W S=1-\sum_{i=1}^{N} 2^{-x_{i}} \frac{\left|x_{i}-y_{i}\right|}{\max \left(\left|x_{i}-1\right|,\left|x_{i}-N\right|\right)}
$$

\section{STUDY CASE}

This work aimed to study the effect of three different MCDA methods TOPSIS, VIKOR and COMET, on the evaluation results of 20 different camera models. Data on the evaluation criteria values of the selected camera models were obtained from various websites. The selected quantitative criteria represent camera parameters considered by customers during purchase decisions. In modelling decision problems, a very significant issue is determining the importance of decision criteria. There are methods in the literature to obtain the values of criteria weights [38]. In this study, two objective criteria weighting methods were applied: Mean Weighting, which gives equal weights and Entropy Weighting. The selected criteria according to which the alternatives were evaluated are included in Table II. In the next steps of the study, a comparative analysis between the MCDA methods used was performed for each of the criteria weighting methods used. Finally, two ranking correlation coefficients were used to determine the convergence of the obtained rankings: symmetrical $r_{w}$ and asymmetrical $W S$.

TABLE II

Selected CRiteria USED IN EVALUATION OF CAMERA Models

\begin{tabular}{lrrr}
\hline$C_{i}$ & Name & Type & Unit \\
\hline$C_{1}$ & Thickness & Cost & Millimeters $[\mathrm{mm}]$ \\
$C_{2}$ & Width & Cost & Millimeters $[\mathrm{mm}]$ \\
$C_{3}$ & Height & Cost & Millimeters $[\mathrm{mm}]$ \\
$C_{4}$ & Weight & Cost & Gram $[\mathrm{g}]$ \\
$C_{5}$ & Resolution & Profit & Megapixel [Mpx] \\
$C_{6}$ & $4 \mathrm{~K}$ & Profit & Frames per second [FPS] \\
$C_{7}$ & FullHD & Profit & Frames per second [FPS] \\
$C_{8}$ & HD & Profit & Frames per second [FPS] \\
$C_{9}$ & Viewing angle & Profit & Radian [] \\
$C_{10}$ & Battery life & Profit & Minutes [min] \\
$C_{11}$ & Price & Cost & Polish zloty [PLN] \\
\hline
\end{tabular}

\section{RESUlts AND Discussion}

The values of each criterion for the alternatives evaluated are given in the decision matrix, displayed in Table III. The decision matrix, normalized by using the MinimumMaximum normalization method for each weighting technique and MCDA method, is presented in Table IV. For the TOPSIS and COMET methods, the best alternative is the alternative that scored the highest preference value. Therefore, the lower the preference value, the lower the alternative is ranked. For the VIKOR method, the opposite is true. In its case, 
TABLE III

The Performance table of THE Alternatives $A_{1}-A_{20}$.

\begin{tabular}{|c|c|c|c|c|c|c|c|c|c|c|c|}
\hline Alternatives & $C_{1}$ & $C_{2}$ & $C_{3}$ & $C_{4}$ & $C_{5}$ & $C_{6}$ & $C_{7}$ & $C_{8}$ & $C_{9}$ & $C_{10}$ & $C_{11}$ \\
\hline SONY FDR-X3000 & 29.40 & 83.00 & 47.00 & 114 & 12.0 & 30 & 120 & 240 & 170 & 90 & 1717.75 \\
\hline DJI Pocket 2 Creator Combo & 30.00 & 38.10 & 124.70 & 117 & 16.0 & 60 & 60 & 60 & 93 & 70 & 2389.00 \\
\hline GÖTZE \& JENSEN S-Line SC501 & 29.28 & 59.27 & 41.13 & 58 & 16.0 & 30 & 60 & 120 & 170 & 78 & 239.99 \\
\hline GOPRO HERO9 & 33.60 & 71.00 & 55.00 & 159 & 23.6 & 60 & 240 & 240 & 132 & 140 & 2099.00 \\
\hline Xblitz Move 4K+ & 21.00 & 59.00 & 41.00 & 66 & 16.0 & 24 & 60 & 120 & 170 & 70 & 439.00 \\
\hline DJI Osmo Action & 35.00 & 65.00 & 42.00 & 134 & 12.0 & 60 & 240 & 240 & 145 & 60 & 1087.00 \\
\hline Insta360 ONE R-1-Inch Edition & 47.00 & 79.00 & 54.00 & 158 & 19.0 & 60 & 120 & 120 & 360 & 72 & 2499.00 \\
\hline GOPRO HERO7 & 28.30 & 62.30 & 44.90 & 116 & 12.0 & 30 & 60 & 60 & 130 & 90 & 999.99 \\
\hline DJI Osmo Pocket & 36.90 & 28.60 & 121.60 & 130 & 12.0 & 60 & 120 & 120 & 80 & 80 & 1099.00 \\
\hline GOXTREME Enduro & 32.00 & 59.00 & 41.00 & 60 & 16.0 & 30 & 120 & 120 & 170 & 60 & 302.96 \\
\hline GOPRO HERO8 & 28.40 & 66.30 & 48.60 & 126 & 12.0 & 60 & 240 & 240 & 132 & 135 & 1629.00 \\
\hline Insta360 One $\mathrm{X} 2$ & 29.80 & 46.00 & 113.00 & 47 & 18.0 & 50 & 50 & 50 & 360 & 72 & 2099.00 \\
\hline SJCAM A20 & 20.20 & 64.00 & 80.00 & 70 & 8.0 & 24 & 60 & 120 & 166 & 480 & 699.99 \\
\hline LAMAX X9.1 & 33.00 & 60.00 & 44.00 & 59 & 12.0 & 30 & 60 & 120 & 170 & 90 & 388.00 \\
\hline MANTA MM9259 & 29.00 & 59.00 & 41.00 & 55 & 16.0 & 30 & 60 & 120 & 170 & 120 & 299.00 \\
\hline SJCAM SJ4000 WiFi & 29.00 & 59.00 & 41.00 & 182 & 12.0 & 30 & 30 & 60 & 94 & 140 & 249.00 \\
\hline LAMAX Action X3.1 Atlas & 29.80 & 59.20 & 41.00 & 65 & 16.0 & 30 & 60 & 120 & 160 & 90 & 219.99 \\
\hline SJCAM SJ10 Pro & 28.80 & 62.50 & 41.00 & 70 & 12.0 & 60 & 120 & 120 & 170 & 138 & 1399.99 \\
\hline GOXTREME Pioneer & 24.00 & 40.00 & 59.00 & 60 & 12.0 & 10 & 30 & 30 & 140 & 78 & 269.99 \\
\hline TRACER eXplore SJ 4561 & 30.00 & 60.00 & 45.00 & 201 & 16.0 & 30 & 30 & 30 & 170 & 90 & 199.99 \\
\hline
\end{tabular}

TABLE IV

NORMALIZED DECISION MATRIX

\begin{tabular}{llllllllllll}
\hline$A_{i}$ & $C_{1}$ & $C_{2}$ & $C_{3}$ & $C_{4}$ & $C_{5}$ & $C_{6}$ & $C_{7}$ & $C_{8}$ & $C_{9}$ & $C_{10}$ & $C_{11}$ \\
\hline$A_{1}$ & 0.3745 & 0.0000 & 0.6231 & 0.4328 & 0.5085 & 0.5000 & 0.5000 & 1.0000 & 0.4722 & 0.1875 & 0.3126 \\
$A_{2}$ & 0.3617 & 0.5410 & 0.0000 & 0.4179 & 0.6780 & 1.0000 & 0.2500 & 0.2500 & 0.2583 & 0.1458 & 0.0440 \\
$A_{3}$ & 0.3770 & 0.2859 & 0.6702 & 0.7114 & 0.6780 & 0.5000 & 0.2500 & 0.5000 & 0.4722 & 0.1625 & 0.9040 \\
$A_{4}$ & 0.2851 & 0.1446 & 0.5589 & 0.2090 & 1.0000 & 1.0000 & 1.0000 & 1.0000 & 0.3667 & 0.2917 & 0.1601 \\
$A_{5}$ & 0.5532 & 0.2892 & 0.6712 & 0.6716 & 0.6780 & 0.4000 & 0.2500 & 0.5000 & 0.4722 & 0.1458 & 0.8243 \\
$A_{6}$ & 0.2553 & 0.2169 & 0.6632 & 0.3333 & 0.5085 & 1.0000 & 1.0000 & 1.0000 & 0.4028 & 0.1250 & 0.5650 \\
$A_{7}$ & 0.0000 & 0.0482 & 0.5670 & 0.2139 & 0.8051 & 1.0000 & 0.5000 & 0.5000 & 1.0000 & 0.1500 & 0.0000 \\
$A_{8}$ & 0.3979 & 0.2494 & 0.6399 & 0.4229 & 0.5085 & 0.5000 & 0.2500 & 0.2500 & 0.3611 & 0.1875 & 0.5998 \\
$A_{9}$ & 0.2149 & 0.6554 & 0.0249 & 0.3532 & 0.5085 & 1.0000 & 0.5000 & 0.5000 & 0.2222 & 0.1667 & 0.5602 \\
$A_{10}$ & 0.3191 & 0.2892 & 0.6712 & 0.7015 & 0.6780 & 0.5000 & 0.5000 & 0.5000 & 0.4722 & 0.1250 & 0.8788 \\
$A_{11}$ & 0.3957 & 0.2012 & 0.6103 & 0.3731 & 0.5085 & 1.0000 & 1.0000 & 1.0000 & 0.3667 & 0.2812 & 0.3481 \\
$A_{12}$ & 0.3660 & 0.4458 & 0.0938 & 0.7662 & 0.7627 & 0.8333 & 0.2083 & 0.2083 & 1.0000 & 0.1500 & 0.1601 \\
$A_{13}$ & 0.5702 & 0.2289 & 0.3585 & 0.6517 & 0.3390 & 0.4000 & 0.2500 & 0.5000 & 0.4611 & 1.0000 & 0.7199 \\
$A_{14}$ & 0.2979 & 0.2771 & 0.6472 & 0.7065 & 0.5085 & 0.5000 & 0.2500 & 0.5000 & 0.4722 & 0.1875 & 0.8447 \\
$A_{15}$ & 0.3830 & 0.2892 & 0.6712 & 0.7264 & 0.6780 & 0.5000 & 0.2500 & 0.5000 & 0.4722 & 0.2500 & 0.8804 \\
$A_{16}$ & 0.3830 & 0.2892 & 0.6712 & 0.0945 & 0.5085 & 0.5000 & 0.1250 & 0.2500 & 0.2611 & 0.2917 & 0.9004 \\
$A_{17}$ & 0.3660 & 0.2867 & 0.6712 & 0.6766 & 0.6780 & 0.5000 & 0.2500 & 0.5000 & 0.4444 & 0.1875 & 0.9120 \\
$A_{18}$ & 0.3872 & 0.2470 & 0.6712 & 0.6517 & 0.5085 & 1.0000 & 0.5000 & 0.5000 & 0.4722 & 0.2875 & 0.4398 \\
$A_{19}$ & 0.4894 & 0.5181 & 0.5269 & 0.7015 & 0.5085 & 0.1667 & 0.1250 & 0.1250 & 0.3889 & 0.1625 & 0.8920 \\
$A_{20}$ & 0.3617 & 0.2771 & 0.6391 & 0.0000 & 0.6780 & 0.5000 & 0.1250 & 0.1250 & 0.4722 & 0.1875 & 0.9200 \\
\hline
\end{tabular}

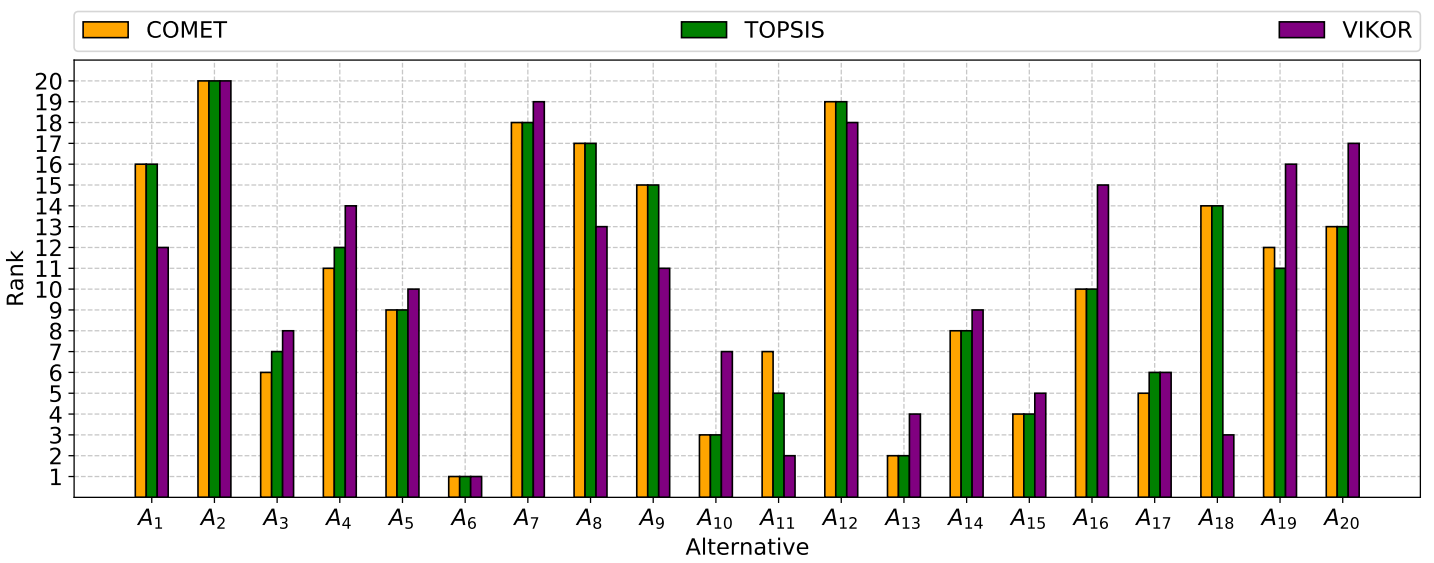

Fig. 1. Comparison of rankings received with using Entropy Weighting for TOPSIS, VIKOR and COMET 
TABLE V

PREFERENCE VALUES AND RANKINGS OBTAINED WITH USING ENTROPY WEIGHTING FOR TOPSIS, VIKOR AND COMET

\begin{tabular}{|c|c|c|c|c|c|c|}
\hline$A_{i}$ & $C O M E T_{\text {pref }}$ & TOPSIS $S_{\text {pref }}$ & $V I K O R_{\text {pref }}$ & $C O M E T_{\text {rank }}$ & TOPSIS $S_{\text {rank }}$ & $V I K O R_{\text {rank }}$ \\
\hline$A_{1}$ & 0.3902 & 0.4287 & 0.3557 & 16 & 16 & 12 \\
\hline$A_{2}$ & 0.0848 & 0.2060 & 0.9500 & 20 & 20 & 20 \\
\hline$A_{3}$ & 0.5901 & 0.5424 & 0.2118 & 6 & 7 & 8 \\
\hline$A_{4}$ & 0.4709 & 0.4853 & 0.4203 & 11 & 12 & 14 \\
\hline$A_{5}$ & 0.5385 & 0.5176 & 0.2609 & 9 & 9 & 10 \\
\hline$A_{6}$ & 0.6677 & 0.5885 & 0.1240 & 1 & 1 & 1 \\
\hline$A_{7}$ & 0.1787 & 0.3136 & 0.8273 & 18 & 18 & 19 \\
\hline$A_{8}$ & 0.3827 & 0.4192 & 0.3778 & 17 & 17 & 13 \\
\hline$A_{9}$ & 0.4278 & 0.4459 & 0.3531 & 15 & 15 & 11 \\
\hline$A_{10}$ & 0.6377 & 0.5703 & 0.2029 & 3 & 3 & 7 \\
\hline$A_{11}$ & 0.5796 & 0.5463 & 0.1397 & 7 & 5 & 2 \\
\hline$A_{12}$ & 0.1631 & 0.2806 & 0.6954 & 19 & 19 & 18 \\
\hline$A_{13}$ & 0.6489 & 0.5877 & 0.1506 & 2 & 2 & 4 \\
\hline$A_{14}$ & 0.5619 & 0.5302 & 0.2232 & 8 & 8 & 9 \\
\hline$A_{15}$ & 0.5988 & 0.5494 & 0.1856 & 4 & 4 & 5 \\
\hline$A_{16}$ & 0.4969 & 0.4978 & 0.4415 & 10 & 10 & 15 \\
\hline$A_{17}$ & 0.5964 & 0.5459 & 0.1976 & 5 & 6 & 6 \\
\hline$A_{18}$ & 0.4580 & 0.4682 & 0.1433 & 14 & 14 & 3 \\
\hline$A_{19}$ & 0.4687 & 0.4856 & 0.4451 & 12 & 11 & 16 \\
\hline$A_{20}$ & 0.4641 & 0.4850 & 0.4674 & 13 & 13 & 17 \\
\hline
\end{tabular}
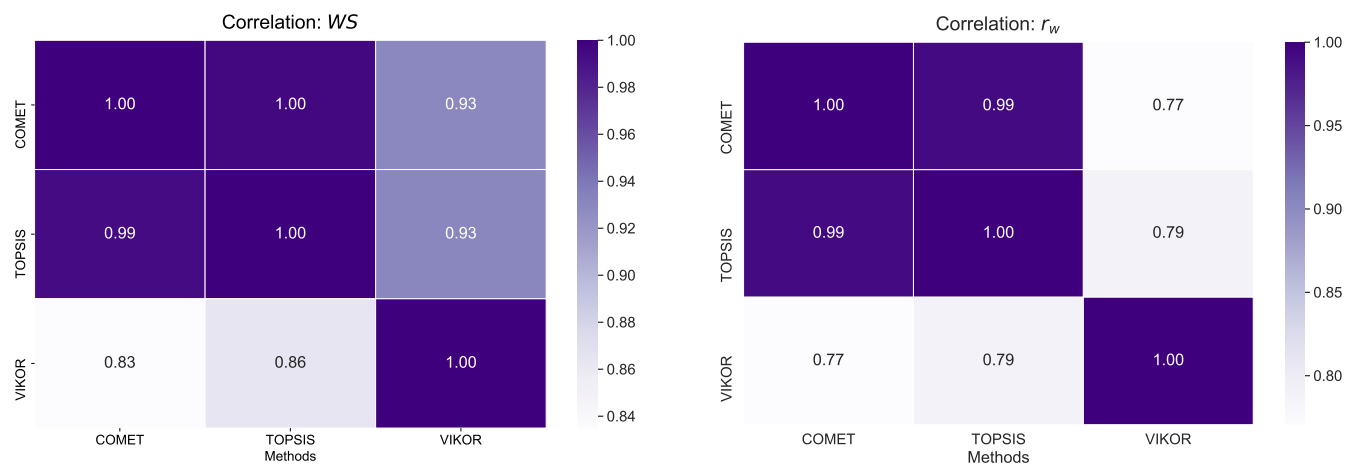

Fig. 2. $W S$ and $r_{w}$ correlation heat maps for TOPSIS, VIKOR and COMET with using Entropy Weighting

TABLE VI

Preference Values and Rankings obtained with using Mean Weighting (Equal Weights) FOR TOPSiS, VIKOR ANd COMET

\begin{tabular}{|c|c|c|c|c|c|c|}
\hline$A_{i}$ & $C O M E T_{\text {pref }}$ & TOPSIS $S_{\text {pref }}$ & $V I K O R_{\text {pref }}$ & $C O M E T_{\text {rank }}$ & TOPSIS rank & $V I K O R_{\text {rank }}$ \\
\hline$A_{1}$ & 0.4516 & 0.4646 & 0.7887 & 13 & 13 & 14 \\
\hline$A_{2}$ & 0.3565 & 0.4042 & 1.0000 & 20 & 20 & 20 \\
\hline$A_{3}$ & 0.5323 & 0.5233 & 0.4939 & 8 & 8 & 6 \\
\hline$A_{4}$ & 0.5797 & 0.5516 & 0.0356 & 2 & 2 & 2 \\
\hline$A_{5}$ & 0.5358 & 0.5249 & 0.5375 & 7 & 7 & 9 \\
\hline$A_{6}$ & 0.5731 & 0.5487 & 0.5186 & 3 & 3 & 8 \\
\hline$A_{7}$ & 0.4353 & 0.4590 & 0.8249 & 15 & 15 & 16 \\
\hline$A_{8}$ & 0.4025 & 0.4248 & 0.7055 & 17 & 18 & 13 \\
\hline$A_{9}$ & 0.4223 & 0.4462 & 0.8539 & 16 & 16 & 17 \\
\hline$A_{10}$ & 0.5421 & 0.5315 & 0.5875 & 6 & 5 & 10 \\
\hline$A_{11}$ & 0.5815 & 0.5565 & 0.0192 & 1 & 1 & 1 \\
\hline$A_{12}$ & 0.4814 & 0.4878 & 0.6455 & 12 & 12 & 11 \\
\hline$A_{13}$ & 0.5159 & 0.5111 & 0.6457 & 10 & 10 & 12 \\
\hline$A_{14}$ & 0.4882 & 0.4913 & 0.5150 & 11 & 11 & 7 \\
\hline$A_{15}$ & 0.5424 & 0.5313 & 0.2023 & 5 & 6 & 4 \\
\hline$A_{16}$ & 0.3868 & 0.4232 & 0.9327 & 19 & 19 & 19 \\
\hline$A_{17}$ & 0.5268 & 0.5195 & 0.4292 & 9 & 9 & 5 \\
\hline$A_{18}$ & 0.5459 & 0.5351 & 0.0790 & 4 & 4 & 3 \\
\hline$A_{19}$ & 0.4393 & 0.4630 & 0.8160 & 14 & 14 & 15 \\
\hline$A_{20}$ & 0.3923 & 0.4281 & 0.9205 & 18 & 17 & 18 \\
\hline
\end{tabular}




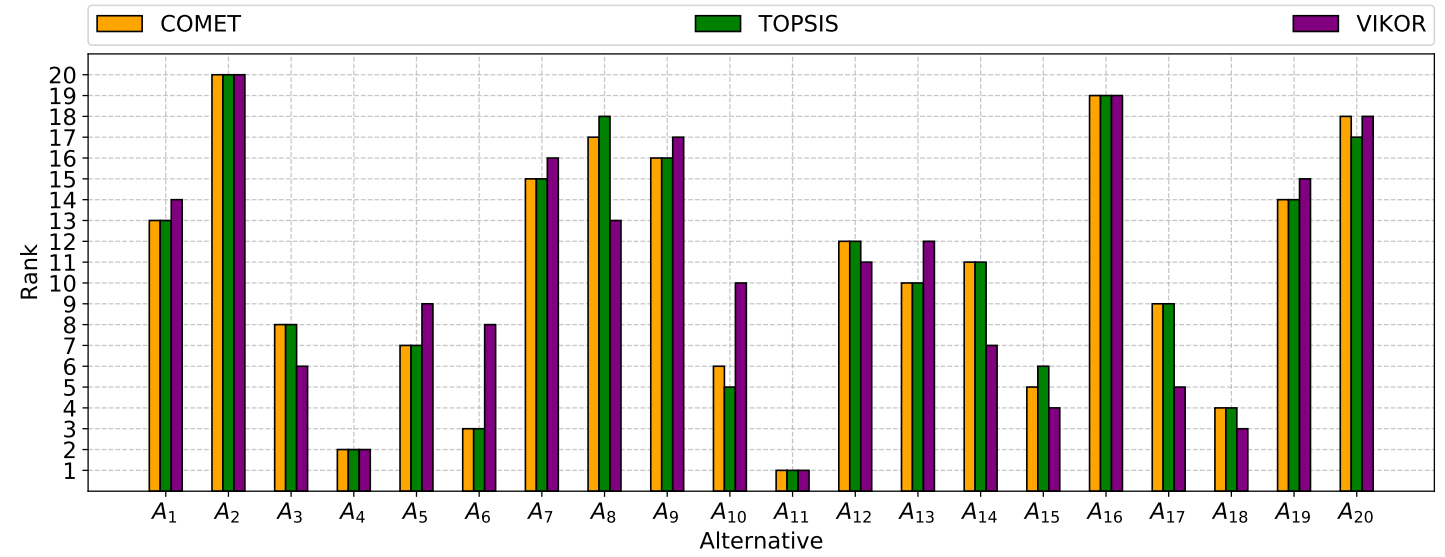

Fig. 3. Comparison of rankings received with using Mean Weighting (Equal Weights) for TOPSIS, VIKOR and COMET
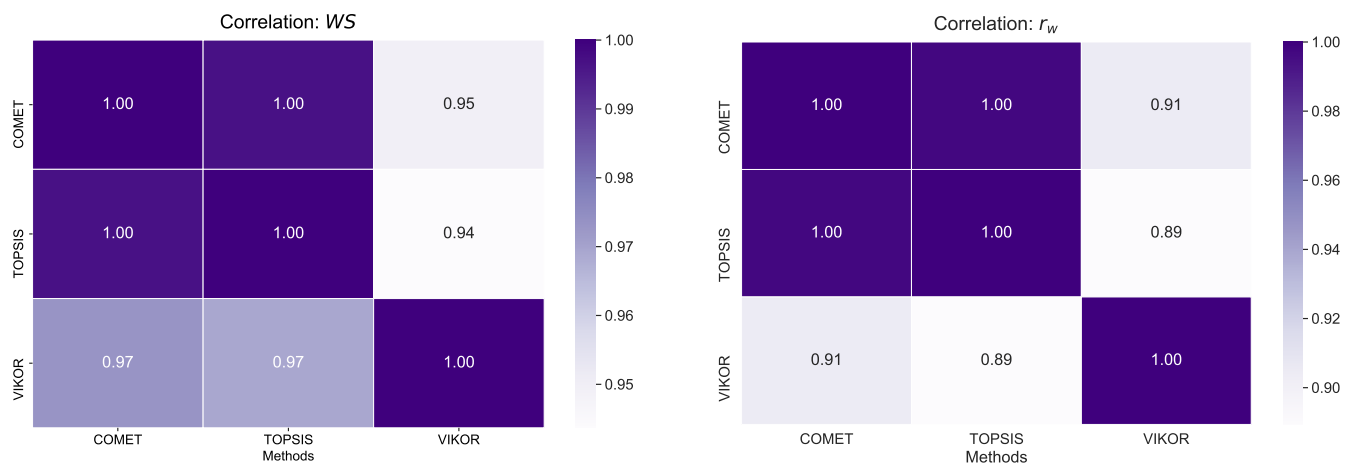

Fig. 4. $W S$ and $r_{w}$ correlation heat maps for TOPSIS, VIKOR and COMET with using Mean Weighting (Equal Weights)

the best alternative is the alternative for which the lowest preference value was calculated. Therefore, as the preference value increases, the alternative decreases in ranking.

\section{A. Results for Entropy Weighting}

Preference values and rankings obtained for each MCDA method with applying entropy weights are contained in Table V. Comparison of rankings is visualized in Figure 1. In the rankings obtained using entropy weights, only two alternatives ranked equally in the rankings created by the MCDA methods applied. These include $A_{6}$, which is the leader in all three rankings, and $A_{2}$, which is always last. Analysis of the obtained rankings allows us to conclude that the VIKOR method has the most significant impact on the differences in rankings. Ranking received using this method demonstrates the most divergent values (range of differences including four positions for $A_{1}$, $A_{8}, A_{9}, A_{10}, A_{20}$, five positions for $A_{11}, A_{16}$, and eleven positions for $A_{18}$ ). The rankings obtained using TOPSIS and COMET methods show very high convergence. As many as 15 alternatives are in identical positions. For the remaining alternatives, the differences are minimal (one position for $A_{3}$, $A_{4}, A_{17}, A_{19}$ and two positions for $A_{11}$ ).
The similarity between the rankings obtained using each MCDA method was then examined. Results of investigation of rankings' similarity are displayed in Figure 2. Two ranking similarity coefficients were used to investigate the correlation: $W S$ and $r_{w}$. The highest value of asymmetrical $W S$ coefficient was noticed for COMET and TOPSIS (1.00) and TOPSIS and COMET (0.99). The lower value was received for COMET and VIKOR and TOPSIS and VIKOR (0.93). The lowest correlation was observed for VIKOR and TOPSIS (0.96) and VIKOR and COMET (0.83).

When investigating the similarity of rankings using the $r_{w}$ coefficient, the highest correlation was found for COMET and TOPSIS (0.99), lower for TOPSIS and VIKOR (0.79), and lowest for VIKOR and COMET (0.77). Thus, the ranking similarity examination results confirm the outliers in the ranking achieved by the VIKOR method.

\section{B. Results for Mean Weighting}

Preference values for TOPSIS, VIKOR and COMET with applying equal weights are contained in Table VI. Comparison of rankings is illustrated in Figure 3. The same rankings for the three MCDA methods were obtained for only four alternatives when Mean Weighting was used. Among them are $A_{11}$, which 
is the ranking leader, $A_{4}$ in second place, $A_{16}$ in second-tolast place, and $A_{2}$ in the last place. Thus, another alternative is the leader for Mean Weighting than Entropy Weighting. The most significant differences between the obtained rankings were observed for the VIKOR method (range of differences including five positions for $A_{6}, A_{8}, A_{10}$, and four positions for $A_{14}$ and $A_{17}$ ). On the other hand, for Mean Weighting, the rankings obtained with the TOPSIS and COMET methods were the most consistent. The rankings were identical for as many as 16 alternatives, while for four alternatives $\left(A_{8}, A_{10}\right.$, $\left.A_{15}, A_{20}\right)$, the differences included only one position.

Values of ranking similarity coefficients are displayed in Figure 4. In the ranking similarity study, the highest $W S$ value was obtained for COMET and TOPSIS (1.00), followed by VIKOR and COMET and VIKOR and TOPSIS (0.97), and the lowest for COMET and VIKOR (0.95) and TOPSIS and VIKOR (0.94). The highest $r_{w}$ value was received for COMET and TOPSIS (1.00), lower for VIKOR and COMET (0.91), and lowest for TOPSIS and VIKOR (0.89).

The results of the performed research demonstrate that the complexity of decision problems containing many different criteria makes it difficult to identify a universal method to obtain the best solution for various problems. Therefore, when there is a need to obtain an objective solution to multi-criteria decision problems, hybrid approaches, in which different algorithms are combined to solve the decision problem, seem to be suitable [40]. A well-known example is the hybrid DSS 3.0 system proposed by Budzinski and Becker. In this system, the values of criteria weights are determined by the AHP method, while the ELECTRE Tri method is used to create the ranking [41]. The described hybrid approach is worth attention and consideration in further research directions.

\section{Conclusions}

This paper aimed to investigate the effect of selected MCDA methods and objective weighting techniques on the objectivity of the resulting rankings. The case study in this work was the camera selection problem. The results obtained confirm that several conditions must be respected to obtain appropriate assessment results using MCDA methods. First, it is essential to select methods for the problem to be adequately solved. Second, benchmarking with other methods allowing for comparative analysis is required. Also, a proper selection of criteria weights that reflect the preferences of the decision-maker is recommended.

The study shows that the most comparable rankings were achieved using TOPSIS and COMET methods. Outlier results of the VIKOR method contribute to the disturbance of objectivity of received results. Due to the careful selection of several MCDA methods and the comparative analysis performed, it was possible to determine a set of methods providing convergent and objective results. Obtained results encourage continuing the research with other MCDA methods to extend the set of methods enabling objectivization of evaluations in the undertaken problem.

\section{ACKNOWLEDGMENT}

The work was supported by the project financed within the framework of the program of the Minister of Science and Higher Education under the name "Regional Excellence Initiative" in the years 2019-2022, Project Number 001/RID/2018/19; the amount of financing: PLN 10.684.000,00 (A.B. and J.W.) and by the National Science Centre, Decision number UMO-2018/29/B/HS4/02725 (B.K. and W.S.).

\section{REFERENCES}

[1] B. Kizielewicz, J. Wątróbski, and W. Sałabun, "Identification of Relevant Criteria Set in the MCDA Process-Wind Farm Location Case Study," Energies, vol. 13, no. 24, p. 6548, 2020. doi: https://doi.org/10.3390/en13246548

[2] J. Wątróbski, P. Ziemba, and W. Wolski, "MCDA-based decision support system for sustainable management-RES case study," in 2016 Federated Conference on Computer Science and Information Systems (FedCSIS), Gdansk, Poland, 11-14 September 2016. IEEE, 2016. doi: https://doi.org/10.15439/2016F489 pp. 1235-1239.

[3] C. Beaudrie, C. J. Corbett, T. A. Lewandowski, T. Malloy, and X. Zhou, "Evaluating the Application of Decision Analysis Methods in Simulated Alternatives Assessment Case Studies: Potential Benefits and Challenges of using MCDA," Integrated Environmental Assessment and Management, vol. 17, no. 1, pp. 27-41, 2021. doi: https://doi.org/10.1002/ieam.4316

[4] A. Karczmarczyk, J. Wątróbski, and J. Jankowski, "Comparative Study of Different MCDA-Based Approaches in Sustainable Supplier Selection Problem," in Information Technology for Management: Emerging Research and Applications. Springer, 2018. doi https://doi.org/10.1007/978-3-030-15154-6_10 pp. 176-193.

[5] N. Tsotsolas and S. Alexopoulos, "MCDA Approaches for Efficient Strategic Decision Making," in Preference Disaggregation in Multiple Criteria Decision Analysis. Springer, 2018. doi: https://doi.org/10.1007/978-3-319-90599-0_2 pp. 17-58.

[6] W. Sałabun, J. Wątróbski, and A. Shekhovtsov, "Are MCDA Methods Benchmarkable? A Comparative Study of TOPSIS, VIKOR, COPRAS, and PROMETHEE II Methods," Symmetry, vol. 12, no. 9, p. 1549, 2020. doi: https://doi.org/10.3390/sym12091549

[7] M. Cinelli, M. Kadziński, M. Gonzalez, and R. Słowiński, "How to support the application of multiple criteria decision analysis? Let us start with a comprehensive taxonomy," Omega, p. 102261, 2020. doi https://doi.org/10.1016/j.omega.2020.102261

[8] A. Papapostolou, F. D. Mexis, E. Sarmas, C. Karakosta, and J. Psarras, "Web-based Application for Screening Energy Efficiency Investments: A MCDA Approach," in 2020 11th International Conference on Information, Intelligence, Systems and Applications (IISA), Piraeus, Greece, 15-17 July 2020. IEEE, 2020. doi: https://doi.org/10.1109/IISA50023.2020.9284403 pp. 1-7.

[9] J. Wątróbski, J. Jankowski, P. Ziemba, A. Karczmarczyk, and M. Zioło, "Generalised framework for multi-criteria method selection," Omega, vol. 86, pp. 107-124, 2019. doi https://doi.org/10.1016/j.omega.2018.07.004

[10] R. K. Dhurkari, "MCGL: a new reference dependent MCDM method," International Journal of Operational Research, vol. 36, no. 4, pp. 477 495, 2019. doi: https://doi.org/10.1504/IJOR.2019.104053

[11] B. Roy, "Classement et choix en présence de points de vue multiples," Revue française d'informatique et de recherche opérationnelle, vol. 2, no. 8, pp. 57-75, 1968. doi: http://www.numdam.org/item?id=RO_1968_2_1_57_0

[12] J.-P. Brans and P. Vincke, "Note-a preference ranking organisation method: (the promethee method for multiple criteria decisionmaking)," Management science, vol. 31, no. 6, pp. 647-656, 1985. doi: https://doi.org/10.1287/mnsc.31.6.647

[13] J.-M. Martel and B. Matarazzo, "Other outranking approaches," in Multiple criteria decision analysis: state of the art surveys. Springer, 2005. doi: https://doi.org/10.1007/978-1-4939-3094-4_7 pp. 197-259. 
[14] A. Darko, A. P. C. Chan, E. E. Ameyaw, E. K. Owusu, E. Pärn, and D. J. Edwards, "Review of application of analytic hierarchy process (ahp) in construction," International journal of construction management, vol. 19, no. 5, pp. 436-452, 2019. doi: https://doi.org/10.1080/15623599.2018.1452098

[15] C.-L. Hwang and K. Yoon, "Methods for multiple attribute decision making," in Multiple attribute decision making. Springer, 1981. doi: https://doi.org/10.1007/978-3-642-48318-9_3 pp. 58-191.

[16] L. Duckstein and S. Opricovic, "Multiobjective optimization in river basin development," Water resources research, vol. 16, no. 1, pp. 1420, 1980. doi: https://doi.org/10.1029/WR016i001p00014

[17] N. Sinha, N. Priyanka, and P. Joshi, "Using spatial multi-criteria analysis and ranking tool (SMART) in earthquake risk assessment: A case study of Delhi region, India," Geomatics, Natural Hazards and Risk, vol. 7, no. 2, pp. 680-701, 2016. doi: https://doi.org/10.1080/19475705.2014.945100

[18] S. Greco, "A new PCCA method: Idra," European Journal of Operational Research, vol. 98, no. 3, pp. 587-601, 1997. doi: https://doi.org/10.1016/S0377-2217\%2896\%2900022-7

[19] H. Voogd, "Multicriteria evaluation with mixed qualitative and quantitative data," Environment and Planning B: Planning and Design, vol. 9, no. 2, pp. 221-236, 1982. doi: https://doi.org/10.1068/b090221

[20] A. Giarlotta, "Passive and active compensability multicriteria annalysis (PACMAN)," Journal of Multi-Criteria Decision Analysis, vol. 7, no. 4, pp. 204-216, 1998. doi: https://doi.org/10.1002/\%28SICI\%291099$1360 \% 28199807 \% 297: 4 \% 3 C 204:: A I D-M C D A 192 \% 3 E 3.0 . C O \% 3 b 2-5$

[21] P. Fortemps, S. Greco, and R. Słowiński, "Multicriteria choice and ranking using decision rules induced from rough approximation of graded preference relations," in International Conference on Rough Sets and Current Trends in Computing, Uppsala, Sweden, 1-5 June 2004. Springer, 2004. doi: https://doi.org/10.1007/978-3-540-25929-9_62 pp. 510-522.

[22] W. Sałabun, "The Characteristic Objects Method: A New Distancebased Approach to Multicriteria Decision-making Problems," Journal of Multi-Criteria Decision Analysis, vol. 22, no. 1-2, pp. 37-50, 2015. doi: https://doi.org/10.1002/mcda.1525

[23] W. Sałabun and A. Piegat, "Comparative analysis of MCDM methods for the assessment of mortality in patients with acute coronary syndrome," Artificial Intelligence Review, vol. 48, no. 4, pp. 557-571, 2017. doi: https://doi.org/10.1007/s10462-016-9511-9

[24] J. Wątróbski and J. Jankowski, "Knowledge management in MCDA domain," in 2015 Federated Conference on Computer Science and Information Systems (FedCSIS), Lodz, Poland, 13-16 September 2015. IEEE, 2015. doi: https://doi.org/10.15439/2015F295 pp. 1445-1450.

[25] A. Karczmarczyk, J. Wątróbski, G. Ladorucki, and J. Jankowski, "MCDA-based approach to sustainable supplier selection," in 2018 Federated Conference on Computer Science and Information Systems (FedCSIS), Poznan, Poland, 9-12 September 2018. IEEE, 2018. doi: https://doi.org/10.15439/2018F336 pp. 769-778.

[26] V. Yadav, S. Karmakar, P. P. Kalbar, and A. K. Dikshit, "PyTOPS: A Python based tool for TOPSIS," SoftwareX, vol. 9, pp. 217-222, 2019. doi: https://doi.org/10.1016/j.softx.2019.02.004

[27] T. Imandasari, M. G. Sadewo, A. P. Windarto, A. Wanto, H. O. L. Wijaya, and R. Kurniawan, "Analysis of the Selection Factor of Online Transportation in the VIKOR Method in Pematangsiantar city," in Journal of Physics: Conference Series, Niagara Hotel, Parapat, Indonesia, 10-12 October 2018, vol. 1255, no. 1. IOP Publishing, 2019. doi: https://doi.org/10.1088/1742-6596/1255/1/012008 p. 012008.

[28] A. Mardani, E. K. Zavadskas, K. Govindan, A. Amat Senin, and A. Jusoh, "VIKOR technique: A systematic review of the state of the art literature on methodologies and applications," Sustainability, vol. 8, no. 1, p. 37, 2016. doi: https://doi.org/10.3390/su8010037
[29] D. Siregar, H. Nurdiyanto, S. Sriadhi, D. Suita, U. Khair, R. Rahim, D. Napitupulu, A. Fauzi, A. Hasibuan, M. Mesran et al., "Multi-attribute decision making with VIKOR method for any purpose decision," in Journal of Physics: Conference Series, Kuching, Sarawak, Malaysia, 25-27 November 2017, vol. 1019, no. 1. IOP Publishing, 2018. doi: https://doi.org/10.1088/1742-6596/1019/1/012034 p. 012034.

[30] M. Kumar and C. Samuel, "Selection of best renewable energy source by using VIKOR method," Technology and Economics of Smart Grids and Sustainable Energy, vol. 2, no. 1, p. 8, 2017. doi: https://doi.org/10.1007/s40866-017-0024-7

[31] J. Wątróbski, W. Sałabun, A. Karczmarczyk, and W. Wolski, "Sustainable decision-making using the COMET method: An empirical study of the ammonium nitrate transport management," in 2017 Federated Conference on Computer Science and Information Systems (FedCSIS), Prague, Czech Republic, 3-6 September 2017. IEEE, 2017. doi: https://doi.org/10.15439/2017F455 pp. 949-958.

[32] W. Sałabun, J. Wątróbski, and A. Piegat, "Identification of a multicriteria model of location assessment for renewable energy sources," in International Conference on Artificial Intelligence and Soft Computing, Zakopane, Poland, 12-16 June 2016. Springer, 2016. doi: https://doi.org/10.1007/978-3-319-39378-0_28 pp. 321-332.

[33] W. Sałabun, P. Ziemba, and J. Wątróbski, "The rank reversals paradox in management decisions: The comparison of the AHP and COMET methods," in International Conference on Intelligent Decision Technologies, Tenerife, Spain, 15-17 June 2016. Springer, 2016. doi: https://doi.org/10.1007/978-3-319-39630-9_15 pp. 181-191.

[34] W. Sałabun, A. Karczmarczyk, J. Wątróbski, and J. Jankowski, "Handling data uncertainty in decision making with COMET," in 2018 IEEE Symposium Series on Computational Intelligence (SSCI), Bangalore, India, 18-21 November 2018. IEEE, 2018. doi: https://doi.org/10.1109/SSCI.2018.8628934 pp. 1478-1484.

[35] A. Shekhovtsov, J. Kołodziejczyk, and W. Sałabun, "Fuzzy Model Identification Using Monolithic and Structured Approaches in Decision Problems with Partially Incomplete Data," Symmetry, vol. 12, no. 9, p. 1541, 2020. doi: https://doi.org/10.3390/sym12091541

[36] H. Li, W. Wang, L. Fan, Q. Li, and X. Chen, "A novel hybrid MCDM model for machine tool selection using fuzzy DEMATEL, entropy weighting and later defuzzification VIKOR," Applied Soft Computing, vol. 91, p. 106207, 2020. doi: https://doi.org/10.1016/j.asoc.2020.106207

[37] N. Yalcin and U. Ünlü, "A multi-criteria performance analysis of Initial Public Offering (IPO) firms using CRITIC and VIKOR methods," Technological and Economic development of Economy, vol. 24, no. 2, pp. 534-560, 2018. doi: http://dx.doi.org/10.3846/20294913.2016.1213201

[38] A. Shekhovtsov, V. Kozlov, V. Nosov, and W. Sałabun, "Efficiency of Methods for Determining the Relevance of Criteria in Sustainable Transport Problems: A Comparative Case Study," Sustainability, vol. 12, no. 19 , p. 7915 , 2020. doi: https://doi.org/10.3390/su12197915

[39] W. Sałabun and K. Urbaniak, "A new coefficient of rankings similarity in decision-making problems," in International Conference on Computational Science, Amsterdam, The Netherlands, 3-5 June 2020. Springer, 2020. doi: https://doi.org/10.1007/978-3-030-50417-5_47 pp. 632-645.

[40] J. Becker and R. Budziński, "Optimization Procedure of the Multiparameter Assessment and Bidding of Decision-Making Variants in the Computerized Decision Support System," in Computational Collective Intelligence. Springer, 2015. doi: https://doi.org/10.1007/978-3-31924306-1_18 pp. 182-192.

[41] L. Fabisiak, R. Budziński, K. Szczypiór-Piasecka, and P. Ziętek, "Zastosowanie metody wielokryterialnej do analizy diagnostycznej pacjenta z chorobą zwyrodnieniową stawu biodrowego," Studia Informatica Pomerania, no. 4 (42), pp. 15-25, 2016. doi: http://dx.doi.org/10.18276/si.2016.42-02 